\title{
Research on the Use Efficiency of Scientific Research Funding for Colleges and Universities Based on DEA Model
}

\author{
Yanjun Tong \\ Audit Office, Neijiang Normal University, Neijiang, Sichuan, 641100, China \\ 4280004@qq.com
}

Keywords: DEA model; Colleges and universities; Scientific research funding

\begin{abstract}
At present, under the background of the high attention paid to the use efficiency of scientific research funding in various sectors of our society, how to effectively evaluate the use efficiency of scientific research funding in colleges and universities has become a key point which reflects whether the allocation of scientific research funding is balanced among colleges and universities, and reflects whether the direction and proportion of scientific research funding in a single university are reasonable. DEA model can well solve the problem of input-output evaluation in the use efficiency of scientific research funding in colleges and universities. Therefore, we specially select DEA model to evaluate the efficiency of scientific research funding in colleges and universities, and select the research input index from four aspects: researchers, research funding, research platform and research projects.
\end{abstract}

\section{Introduction}

Scientific research funding is necessary for scientific research and material basis. Compared with the western countries, due to the special national conditions, $80 \%$ of our research funding and research tasks are concentrated in colleges and universities and research institutes, enterprises only take a small part. Colleges and universities have strong scientific research advantages. In Colleges and universities (especially research universities), scholars and scientists of various disciplines have been gathered, and they have modern scientific and technological means. A large number of young students with innovative ability have joined the team of scientific research, so the position of colleges and universities in the development of science and technology in our country has become more and more important. The National Medium and Long-Term Scientific and Technological Development Plan (2006-2020) clearly states that: "The university is an important base for cultivating high-level innovative personnel in our country and one of the main forces in the initial innovation in basic research and high-tech fields in our country. It can solve the major scientific and technological problems in the national economy and it is a vital force for technology transfer and transformation achievements. Speeding up the construction of a number of high-level universities, especially a batch of world-renowned high-level research universities, is the need of China to speed up scientific and technological innovation and build a national innovation system." This shows the significance and role of colleges and universities in national scientific and technological innovation. With the increasing investment in science and technology in our country and the continuous deepening of the reform of science and technology system, the capability of science and technology innovation has been further enhanced and the number of scientific and technological achievements has grown remarkably. As an important part of the national science and technology innovation system, colleges and universities have exported a large number of scientific research achievements since their implementation of the "National Strategy of Rejuvenating China through Science and Education", "985 Project", "211 Project" and "Collaborative Innovation". Taking Sichuan's universities as an example, the overall scientific and technological strength and overall competitiveness of Sichuan universities in 2013 ranked among the top 10 in the country, with 38,615 scientific research projects undertaken, ranking sixth in the country and first in western China. There were 302 state-level projects that passed the acceptance inspection and ranked the sixth in the country with the most outstanding accomplishments in accomplishing major national 
science and technology tasks. Among them, the national support plan ranked the first in the country and the 973 plan ranked the third in the country. Colleges and universities in Sichuan made new breakthroughs in winning the highest science and technology award for science and technology in the country and the province. It won 11 national three major scientific and technological awards and won 100 provincial awards for science and technology. Sichuan Province won the only science and technology outstanding contribution award and the only science and technology progress prize. Their technology transfer contract value reached 218 million yuan, ranking the fifth in the country. The actual income ranked the fifth in the country and the first in western region. Colleges and universities in Sichuan directly solved the first-tier practical technical problems and raised a total of RMB5.711 billion of scientific and technological funding through various channels. Among them, the research and development funding entrusted by enterprises and industries are the fourth in the country. It undertook 20,884 research and development (R \& D) projects that embodied its core competitiveness and sustainable development capability, ranking the seventh in the country. The funding reached 4.444 billion yuan, ranking the fifth in the country. The province achieved 1.3625 million employment through the transformation of scientific and technological achievements of colleges and universities, accounting for $2.83 \%$ of the province, boosted exports of 1.192 billion U.S. dollars, accounting for $2.79 \%$ of the province's total revenue, achieved 6.456 billion yuan of tax revenue, accounting for $3.07 \%$ of the province's total and drove industrial investment of 58.401 billion yuan, accounting for $2.77 \%$ of the province, achieved an output value of 74.578 billion yuan, accounting for $29 \%$ of the province's similar output value, and drove GDP growth by 0.51 percentage point. Scientific research at colleges and universities has become an indispensable and important link supporting the increasingly large scientific research system in the country and occupies a unique and important position in the scientific research system and active development of our country.

Nevertheless, due to the deep-seated and structural problems in the management system for the development of science and technology in our country, $78 \%$ of the funding for scientific research in colleges and universities has been used illegally and misappropriated in the course of their use (the data are from the survey results of the China Association for Science and Technology). In the long run, it is bound to seriously restrict the progress of science and technology and the healthy development of economy in Chinese universities. Therefore, it is very necessary to make in-depth study and analysis of the use efficiency of scientific research funding in colleges and universities, to find out the characteristics and laws of the operation of scientific research activities and to find the problems and shortcomings in the operation of the system so as to put forward corresponding policy recommendations for the better understanding of relevant departments of education and scientific research. It is necessary for universities to carry out scientific research to guide the disbursement of scientific research funding in colleges and universities, optimize the allocation of scientific research funding in colleges and universities, improve the use efficiency of scientific research funding in colleges and universities, improve the capability of scientific and technological innovation in colleges and universities and promote the advancement of science and technology in China. This paper studies "the use efficiency of scientific research funding in colleges and universities." We have ruled out the interference of other resources invested in scientific research on the evaluation of the use efficiency of the funding. Considering that scientific research funding included in research investment are all expenditures, we divide the research funding according to the type of expenditure and design it as an input index. We have constructed an input-output index system for the use efficiency of research funding to make the evaluation results more specific, so as to directly and effectively reflect the impact of research funding on output. This greatly enriches and perfects the theory and index system of university research funding efficiency. We study and effectively evaluate "the use efficiency of scientific research funding", and directly test its effectiveness. This reflects whether the allocation of scientific research funding is balanced among colleges and universities, and reflects whether the direction and proportion of scientific research funding in a single university are reasonable, so as to provide a reference for the rational allocation of scientific research funding and the determination of a reasonable structure of funding within colleges and 
universities by relevant departments of finance and education.

\section{The Establishment of the Model}

Data envelopment analysis (DEA) is a new performance evaluation method developed by the famous American operations research scientist A. Charnes in 1978 based on the concept of relative efficiency. This method takes the weight coefficient of input index and output index of decision-making unit as variables. With the help of mathematical programming model, the decision-making unit is projected to the forefront of DEA production. By comparing the deviation of decision-making unit from the front of DEA production, the relative effectiveness of the decision-making unit under evaluation is evaluated comprehensively. The basic idea is: through the comprehensive analysis of input-output data, we can get the quantitative index of the relative efficiency of each DMU, and determine whether each DMU is valid for DEA.

We mainly introduce the most basic DEA model - the $C^{2} R$ model. There are n decision-making units $(\mathrm{j}=1,2, \ldots, \mathrm{n})$, each decision-making unit has the same $\mathrm{m}$ input, the input vector is:

$$
x_{j}=\left(x_{1, j}, x_{2 j}, \cdots, x_{m j}\right)^{T}>0, j=1,2, \cdots, n
$$

Each decision-making unit has the same s output, the output vector is:

$$
y_{j}=\left(y_{1 j}, y_{2 j}, \cdots, y_{s j}\right)^{T}>0, j=1,2, \cdots, n
$$

That is, each decision-making unit has m types of "inputs" and s types of "outputs".

$x_{i j}$ represents the input amount of the ith type input by the jth decision-making unit.

$y_{i j}$ represents the output amount of the jth decision-making unit for the ith type of output.

In order to unify all the inputs and outputs, to view the production as a simple production process with only one input and one output, we need to empower each input and output.

We suppose that the weights of input and output are: $v=\left(v_{1}, v_{2}, \cdots, v_{m}\right)^{T}, \boldsymbol{u}=\left(u_{1}, u_{2}, \cdots, u_{s}\right)^{T} . v_{i}$ is the i-type input weight, $u_{r}$ is the r-type output weight.

In this case, the integrated value of the jth decision-making unit is $\sum_{i=1}^{m} v_{i} x_{i j}$, and the integrated value of the output is $\sum_{r=1}^{s} \boldsymbol{u}_{r} y_{r j}$. We define the efficiency evaluation index of each decision unit $D M U_{j}$ as:

$$
\boldsymbol{h}_{j}=\frac{\sum_{r=1}^{s} \boldsymbol{u}_{r} \boldsymbol{y}_{r j}}{\sum_{i=1}^{m} \boldsymbol{v}_{i} \boldsymbol{X}_{i j}}
$$

In this model, $x_{i j}$ and $y_{i j}$ are known numbers (which can be obtained from historical data or forecast data). The problem is to determine a set of optimal weight vectors: $v$ and $u$, to maximize the efficiency value $h_{j}$ of the $j$ th decision-making unit. The maximum efficiency evaluation value is that the decision-making unit is not likely to have higher relative efficiency evaluation than other decision-making units. We define that all $h_{j}$ values $(j=1,2, \ldots, n)$ do not exceed 1 , that is, $\max _{\mathrm{j}} \leq 1$. This means that if the kth decision-making unit $\mathrm{h}_{\mathrm{k}}=1$, the decision-making unit has the highest productivity relative to other decision-making units, or the system is relatively efficient. If $h_{k}<1$, then it is relative to other decision-making unit, the decision-making unit's productivity still needs to be improved, or the production system is not yet valid. 
According to the above analysis, the optimal evaluation model of the relative efficiency of the $\mathrm{j}_{0}$ th decision-making unit is:

$$
\begin{gathered}
\max h_{j_{0}}=\frac{\sum_{r=1}^{s} u_{r} y_{r j_{0}}}{\sum_{i=1}^{m} \nu_{i} x_{i j_{0}}} \\
\text { s.t. }\left\{\begin{array}{c}
\frac{\sum_{r=1}^{s} u_{r} y_{r j}}{\sum_{i=1}^{m} v_{i} x_{i j}} \leq 1, j=1,2, \ldots, n \\
v=\left(v_{1}, v_{2}, \cdots, v_{m}\right)^{T} \geq 0 \\
u=\left(u_{1}, u_{2}, \cdots, u_{s}\right)^{T} \geq 0
\end{array}\right.
\end{gathered}
$$

This is a fractional programming model that we must turn into a linear programming model to solve. Therefore, we make:

$$
t=\frac{1}{\sum_{i=1}^{m} v_{i} x_{i j_{0}}}, \quad \mu_{r}=t u_{r}, \quad w_{i}=t v_{i}
$$

The model is transformed into:

$$
\begin{aligned}
& \max h_{j 0}=\sum_{r=1}^{s} \mu_{r} y_{r j 0} \\
& \text { s.t. }\left\{\begin{array}{l}
\sum_{r=1}^{s} \mu_{r} y_{r j}-\sum_{i=1}^{m} w_{i} x_{i j} \leq 0, \quad j=1,2, \ldots, n \\
\sum_{i=1}^{m} w_{i} x_{i j 0}=1 \\
\mu_{r}, w_{i} \geq 0, \quad i=1,2, . . m ; \quad r=1,2, \ldots, s
\end{array}\right.
\end{aligned}
$$

It was written in the vector form:

$$
\begin{aligned}
& \max h_{j_{0}}=\mu^{T} Y_{0} \\
& \text { s.t. }\left\{\begin{array}{l}
\mu^{T} Y_{j}-w^{T} X_{j} \leq 0 \\
w^{T} X_{0}=1 \\
w \geq 0, \mu \geq 0
\end{array} \quad j=1,2, \ldots, n\right.
\end{aligned}
$$

Suppose the optimal solution of the above problem is $\lambda^{*}, s^{{ }^{*}-}, \theta^{*}$ then the following conclusions and economic implications are:

If $\theta^{*}=1, s^{*+}=0, s^{*-}=0$, the decision-making unit $D M U_{j_{0}}$ is valid for DEA, that is, $w^{*}>0, \mu^{*}>0$ exists in the solution of the original linear programming, and its optimal value $h_{j_{0}}^{*}=1$. At this point, the production of decision unit $D M U_{j_{0}}$ has both technical efficiency and scale efficiency.

But at least one of the input or output slack variables is greater than zero. Then the optimal value of the original linear programming, which is called weak DEA, is valid. It does not have both technical efficiency and scale efficiency at the same time. 
If $\theta^{*}<1$, decision-making unit $D M U_{j_{0}}$ is not DEA valid. Its production activity is neither the best technical efficiency nor the best scale efficiency.

In addition, we can use the best value of $\lambda_{j}$ in $C^{2} R$ model to judge the DMU's scale returns. If $\lambda_{j}^{*}(j=1,2, \cdots, n)$ exists and $\sum \lambda_{j}^{*}=1$ holds, then $D M U_{j_{0}}$ is constant in scale. If $\lambda_{j}^{*}(j=1,2, \cdots, n)$ does not exist and $\sum \lambda_{j}^{*}=1$ holds, then if $\sum \lambda_{j}^{*}<1$, then $D M U_{j_{0}}$ is an increasing the scale efficiency. If $\lambda_{j}^{*}(j=1,2, \cdots, n)$ does not exist and $\sum \lambda_{j}^{*}=1$ holds, then if $\sum \lambda_{j}^{*}<1$, then $D M U_{j_{0}}$ is decreasing the scale efficiency.

\section{The Setting of Indicators}

The Setting of Input Indicators. Based on the characteristics and trends of scientific research performance evaluation indicators selected by domestic and foreign scholars, combined with various literature studies and the feasibility of data acquisition, this dissertation focuses on the scientific research input indicators from the researchers, research funding, research platform and research project. These include: scientific and technological personnel (including the number of postdoctoral stations and full-time equivalent scientific and technical personnel), scientific research platforms (including the number of key laboratories at the national, provincial and ministerial level, municipal level and large-scale equipment for scientific research projects), the funding (including the vertical project funding, horizontal project funding and school funding), research projects(the total number of state-level, provincial and ministerial-level, municipal-level and university-level scientific research projects that school teachers made during that year).

The Setting of Output Indicators . According to the principle of large correlation and high degree of concentration, this paper selects the output indicators of scientific performance evaluation index. This includes: Papers and monographs (mainly including the number of monographs published at national and provincial level, the number of articles published at Nanda, North Kernels and general journals), intellectual property (including the total number of patents granted), achievement and technology transfer (including the number of scientific research achievements or technology transfer), the achievement award (including the achievement of scientific research at the national, provincial, ministerial, and city hall level).

\section{Conclusions}

DEA model can well solve the problem of multi-input-output evaluation in the use efficiency of scientific research funding in colleges and universities. In the present situation that all circles of our society pay close attention to the general trend of scientific management of scientific research funding, we need to continue to think and try reforms to constantly improve the allocation of scientific research funding, management and evaluation mechanism so as to continuously improve the efficiency of scientific research funding in colleges and universities. Only in this way can we effectively improve the optimal input-output ratio of university research funding.

\section{Acknowledgements}

This paper is one of the stage results of the key project of Sichuan Provincial Department of Education, "Research on the Use Efficiency of Scientific Research Funding in Colleges and Universities - Based on the Sample of Provincial Undergraduate Institutions in Sichuan Province" (18SA0098).

\section{References}

[1] J.F.Song: Research on the Evaluation of the Use Efficiency of Scientific Research Funds in Colleges and Universities -- Based on the samples of the colleges and universities directly 
under the Ministry of Education[D], Dalian University of Technology, 2014.(In Chinese)

[2] Q.Q.Zhao, H.Z.Chen, B.Yu, etc: Evaluation of the Use Efficiency of Scientific Research Funds in Regional Colleges and Universities by Using Cross Section Data[J], Science of Science and Management of S.\&.T, 2009,30(9):119-122,171.(In Chinese)

[3] Z.G.Wu and J.P.Jiang: Some Thoughts on Improving the Use Efficiency of Scientific Research Funds in Colleges and Universities[J],Management of Agriculture Science and Technology, 2012, 31(5): 41-43. DOI:10.3969/j.issn. 1001-8611. 2012.05.012.2.(In Chinese)

[4] J.Xu: Study on the Use Efficiency of the Scientific Research Funds in China's Colleges and Universities[D], Nanjing University of Aeronautics and Astronautics, 2010.DOI:10.7666/d.y1825325.(In Chinese)

[5] X.J.Li, B.Wang, J.Y.Xie, etc: Study on the Application of DEA-CCR Model in the Evaluation of the Utilization Efficiency of Scientific Research Funds in Colleges and Universities[J], Education Science, 2015, 31(2):79-85. DOI:10. 3969/j.issn. 1002-8064. 2015.02.013.(In Chinese) 